\title{
Iliopsoas Muscle
}

National Cancer Institute

\section{Source}

National Cancer Institute. Iliopsoas Muscle. NCI Thesaurus. Code C32764.

A combination of two muscles found in the thigh, the iliacus and the psoas major, which have different sites of orig in but a common insertion on the lesser trochanter of the femur. 